THE FUSION BREEDER:

ITS POTENTIAL ROLE AND PROSPECTS

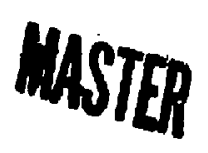

J. D. Lee

This paper was prepared for publication in the Proceedings of the International Workshop on Nuclear Energy Evolution, Sponsorec by the International Institute for Applied System Analys is (IIASA), Schloss Laxenburg, Austria May 25-27, 1981

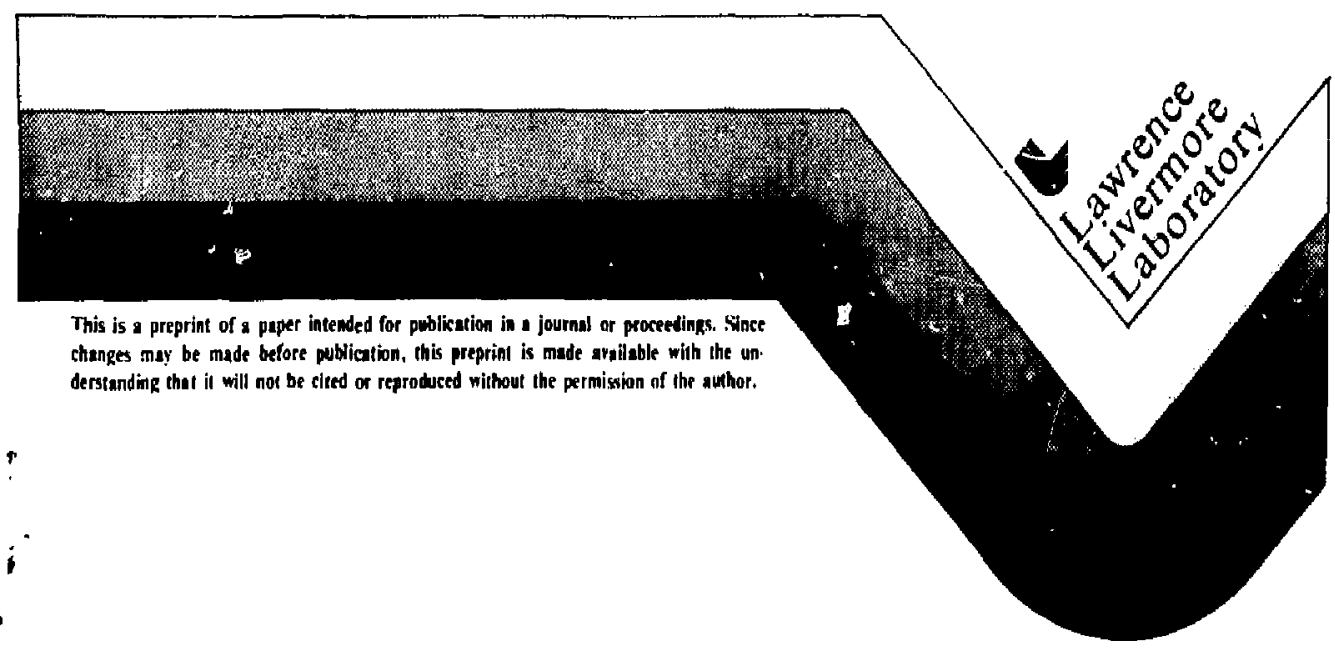


The Fusion Breeder: Its Potential Role and Prospects*

J. D. Lee

Lawrence Livermore National Laboratory

Livermore, CA, USA

The fusion breeder is a concept that utilizes $14 \mathrm{MeV}$ neutrons from $D+T$ $+n(14.1 \mathrm{MeV})+\alpha(3.5 \mathrm{MeV})$ fusion reactions to produce more fuel than the tritium $(T)$ needed to sustain the fusion process. This excess fuel production capacity is used to produce fissile material (Pu-239 or U-233) for subsequent use in fission reactors. We are concentrating on a class of blankets we call fission suppressed. The blanket is the region surrounding the fusion plasma in which fusion neutrons interact to produce fuel and heat.

The fission-suppressed blanket uses non-fission reactions (mainly $(n, 2 n)$ or $\left.\left(n, n^{\prime} t\right)\right)$ tn generate excess neutrons for the production of net fuel. This is in contrast to the fast fission class of blankets which use (n,fiss) reactions to generate excess neutrons. Fusion reactors with fast fission blankets are commonily known as fusion-fission hybrids because they combine fusion and fission in the same device.

Motivation

The motivation for the fusion breeder is basically the same as the fission breeder -- to tap the enormous energy potential of the world's abundant $\mathrm{U}-238$ and Th-232 resources. While the basic motive is the same there are important differences that make the fusion breeder concept most

* Work performed under the auspices of the U.S. Department of Energy by the Lawrence Livermore National Laboratory under Contract W-7405-Eng-48. 
intriguing. For example:

1. The fusion breeder requires no fissile inventory and the doubling time for the fusile inventory (T) is measured in weeks, not years.

2. The fusion breeder can produce many times (up to $\imath 30$ ) more net fissile product per unit of power.

3. Power uensities are 10 to 100 times less.

4. The fusion breeder adds flexibility to the long-term fission energy option. All sorts of fission reactors can be considered, not just fast breeders, by virtue of an inexhaustible, prolific source of fissile material from fusion breeders.

5. The fuel production and trargy production roles are performed in separate devices.

From fusion's viewpoini a motivation for the fusion breeder is the potential for an earlier, competitive application of fusion that in turn would advance fusion technology towards its goal of a stand-a lone energy source. for example, consider a scenario in which the following conditions exist:

- One or more fusion concepts have had a successful engineering demonstration.

- Fission reactor (thermal, such as LWR's, HTGR's) capacity has expanded but now all uranium reserves are committed. Fuel recycie (reprocessing) and advanced isotope separation have already been exploited.

2 The fission fast breeder has been developed but not yet deployed because of its higher cost. 
o The relative energy cost position, in ascending cost, of the major options for additional and replacement capacity is: thermal fission fueled by fusion breeders; fission breeders; coal; fusion.

With this scenario economics would dictate that fission plus fusion breeder reactors would be deployed. If fusion breeder specific technology were not developed, the fission breeder and/or coal would be the logical choice and fusion would not benefit from early deployment. And the economic and environmental costs for power would be higher.

The above scenario, while only an example, does point to the conditions that must exist for fusion breeder deployment. They are:

1. The fusion program must succeed and field an engineering demonstration of fusion.

2. Fission, with reprocessing, must be accepted and have assumed its logical place in the energy mix.

3. Fusion breeder specific technology (blankets and fuel cycles) must be developed and demonstrated.

The fusion breeder could quickly become an important element in the energy system. This is possible vecause one fusion breeder could support the makeup fuel needs of many fission reactors, 15 or more of similar nuclear power. In addition to quick introduction another advantage of high support ratios is that system economics are quite insensitive to performance and cost uncertainties of the fusion breeder. 
The lower power density inherent in the fission-suppressed fusion breeder should simplify design and licensing compared to systems with high fission power densities.

The timely development of the fusion breeder could be considered an insurance policy, insurance to protect against a uranium resource shortfall, and uranium cartels, environmental limitations on coal, economic and deployment limitations on aiternatives such as conservation, solar, or fusion. Preliminary economic analys is suggests the fusion breeder could be competitive with mined uranium when $\mathrm{U}_{3} \mathrm{O}_{8}$ reaches about $100 \$ / 1 \mathrm{~b}$, about twice the cost uranium was selling for a few years ago. The mere existence of a demonstrated fusion breeder technology should put a cap on uranium prices.

The fusion breeder could be beneficial to fission treeder deployment by prov'.ing some or all of their initial fission inventories and thus overcome their doubling time constraints. But at the same time the fission breeder will have to be campetitive with non-breeders for there to be an incentive for deployment. Thus the fusion breeder adds a new dimension to fission and i usion by providing the flexibility of making nan-net breeding fission reactors renewable (long-term) energy optiens, and by allowing fission breeders to be deployed independent of the ir doubling time. This in turn provides an application for fusion that is economically viable, earlier in its development when fusion alone may be 2 to 3 times more expensive.

The national magnetic fusion program is aiming for an engineering demonstration of fusion by the late 1990's. A successful demonstration of 
fusion coupled with development of fusion breeder specific technology would then allow a fusion breeder demor.stration in the 2000-2010 time frame. This is fortuitous because this is about the time frame when a uranium shortfall is predicted to curtail commitment to further conventional nuclear construction.

We believe the fusion breeder could play an important role in our energy future and its economic benefits should far outweigh its overall additional development cost re? ative to the main i ine magnet ic fusion development program.

History.

The idea of marrying fusion and fission was first considered at Livermore by Imhoff' in the early 1950's at the beginning of the fusion program. But the idea was not pursued because large uranium deposits were discovered and fusion was found to be far more difficult to achieve than first perceived. In the early $1960^{\circ} s$ weale ${ }^{2}$ performed integra! experiments with a natural uranium pile and a DT neutron source and measured nuclear reaction rates of 14 MeV neutrons in uranium. In the late 1960's Lidsky at MIT did some studies on fusion-fission and presented the concept of fusion-fission "symbioses." ${ }^{3}$.

At about the same time lee at Livermore started looking at fusion neutron-induced fission of $U-238$ as a way to improve the power balance of low Q fusion systems. ${ }^{4}$ This work culminated with Livermore collaborating with General Atomic in the conceptual design of a "standard mirror" hybrid 
reactor. ${ }^{5}$ This reactor used a minimum B mirror fusion oriver and a fast fission U-238 blanket. The fusion driver operated at $400 \mathrm{MW}$ fusion, oriving the blanket at $3400 \mathrm{MH}$. Net output from this reactor was 600 MHe and $2000 \mathrm{~kg}$ Pu-239 per year (at a capacity factor of 0.74 ).

At this point in Livermore's fusion-fission program, emphas is switched from standard mirror to higher performance tandem mirror fusion drivers ${ }^{6}$ and we also began investigating the fission-suppressed class of fissile-breeding blankets. 7,8 In 1979 Livermore, Bechtel, General Atomic, and General Electric worked together on a conceptual design study of tandem mirror hybrids. This was the first year of a proposed, multi-year study. The first year of this study had two principle purposes. One was to examine the applicability of a low technology $(Q \sim 2)$ tandem mirror as the driver for fusion-fission; the second was to develop and compare conceptual designs of U-233-producing blankets. The result was two conceptual designs, one based on fast fission of thorium, the other on the fission suppression concept. 9 Conclusions reached were that the tandem mirror should make a good driver and that both blanket types resulted in similar attractive economics but had grossly different operating characteristics and feasibility issues. The fission suppression blanket case produced 3 times more fissile fuel (U-233) per unit of nuclear power and its peak fission power density and fission product after heat was? 100 times less for a given fusion neutron current. The high specific fissile production, low fission power density, and low fission product inventory made the fission suppression blanket very attractive.

While the potential performance of fission suppression blankets is 
attractive their feasibility is less certain. The specific blanket concept examined in the 1979 study used Be for neutron multiplication, and a molten salt (LiF-BeF $2-T_{4}$ ) as a mobile fuel and heat trasnfer fluid from which the U-233 (as well as $T$ ) could be removed economically at low concentrations. The feasibility issues of concern are how to protect the Be from the molten salt (MS), how to deal with Be swelling, and what structural material(s) to use to contain the MS. The structural material must also stand up to the fusion neutron environment and not overly reduce breeding. In this design graphite was used to contain sintered Be powder and TZM was chosen for the structure. Graphite is known to be compatible with MS but its radiation resistance is of concern. TZM is known to be compatible with MS and is expected to be reasonably resistant to radiation damage, but there are feasibility issues with TZM fabrication.

Anather concern is molten salt preprocessing technology. It is thought to be feasible but a large-scale development effort will be required for comercialization. Tandem mirror drivers and fission-suppressed blankets were also found to compare favorably to other drivers and blanket types in a 1980 EPRI-spansored Westinghouse-lead feasibility assessment of fusion-fission. 10

The attractive performance of the FY79 fission-suppressed case, tempered by its feasibility and other concerns, set the stage for our FY81 work. The principle objective of this work is to develop fission-suppressed blanket design concepts that performed about as well as the FY79 case but that did not have its feasibility and development concerns. A secondary objective is to 
look at higher performance tandem mirrors as drivers, since with the development of a new tandem concept (thermal barriers) higher performance could be achieved without pushing technology to extremes.

The history described above is intended to summarize how the Livermore fusion breeder concept has evolved. For a more general review of fusion-fission, Refs. 11-13 are recommended.

\section{Fusion-Fission System}

A fusion-fission system cansists of fusion breeders providing fissile inventory and/or make up fuel to fission reactors. The fusion breeder has three major elements:

1. The fusion driver (neutron source)

2. The blanket (for breeding)

3. The fuel cycle (reprocessing and refabrication).

The worid-wide fusion research effort is persuing both magnetic and inertial confirament approaches to commercialize fusion. At present the tokamak and the tandem mirror, both magnetic approaches, are considered the top contenders. All are potential candidates for drivers for fusion-fission. The latest in a series of tokamak commercial reactor design studies is Starfire. $^{14}$ The 3500-MW fusion Starfire design (shown in Fig. 1) is representative of how a tokamak fusion breeder might look. The tandem mirror has an open-ended axial geometry as opposed to tokamak"s closed toroid. The 
conceptual 3000-HW fusion tandem mirror driver show in Fig. 2 shows the tandem's major features. 15

87 ankets for fusion breeders (or fusion-fission hybrids) can have nuclear characteristics that range from fast fission of $\mathrm{U}-238$ for neutron multiplication to fission-suppressed ases that use Be or $\mathrm{Pb}(n, 2 n)$ or $Z_{L i}\left(n, n^{\prime} T\right)$ reactions for the generation of excess neutrons. The breeding ratio and energy release from $14 \mathrm{MeV}$ neutrons with various multipliers is given in Table 1. These are idealized cases in that no blanket engineering requirements are included, i.e., no structure or coolants, etc. U-238 is the most prolific multiplier per $14 \mathrm{MaV}$ neutron while Be gives the highest net fissile production per unit power. Performance estimates for three blanket types, where conceptual enginner ing design requirements are included, are given in Table 2. For an example, the mechanical layout of a conceptual central cell module for a tanderi mirror with a beryllium/molten salt (Be/MS) blanket is shown in Fig. 3.

At this point in the evolution of the fusion breeder concept we believe the fission-suppressed class of blankets has the most potential. This belief is based on the fact that the fission-suppresser blanket has the lowest fission power density and after heat, and the lowest fission product inventory which should simplify design and licensing. It also gives the highest support ratio which should facilitate deployment. Utilities could buy fissile fuel from fusion breeders like they do today from enrichment plants.

A successful fission-suppressed blanket requires that: 
1. Fast fission of fertile material must be suppressed by limiting it: exposure to fast neutrons.

2. An effective non-fission neutran multiplier must be used to generate significant neutrons in excess of those needed to breed tritium to fuel the $0 T$ fusion reaction.

3. Breeding must not be compromised by parasitic neuiron capture.

4. Fissile naterial must be removed at low concentrations to inhibit in-situ fission reactions.

5. Fuel reprocessing and fabrication must be law-cost.

6. Tritium inventory must be kept low to limit its loss due to radioactive decay.

7. Wherever possible, conventional technology should be used to mininize the cost, risk, and time for the necessary development program.

The types of fission reactors that could be fueles (initial inventory and/or makeup) by fusion breeders span the entire spectrum from conventional thermal reactors (LWR, HWR, etc.) to advancs thermal (HTGR, LWBR, etc.) and fast breeders. Conventional fuel cycles can be used as is or modified to make better use of fissile materials. The fusion breeder could provide the U-233 needed for large-scale use of the Th/U fuel cycle in conventional or advanced reacturs.

Now for a specific example of a fusion-fission system. The fusion breeder part of the system has a tandem mirror for the fusion driver, and a beryll ium fission-suppressed blanket with a molten salt fuel cycle. This fusion breeder supplies makeup fuel to LWR's operating on the Th/U-233 with 
t.orex reprocessing and recycle. This fusion breeder has a fusion power of $2700 \mathrm{MH}$ resulting in a total nuclear power of $4000 \mathrm{MW}$. Net electrical and fissile production by this fusion breeder is $1000 \mathrm{MW}$ and $6200 \mathrm{~kg} \mathrm{U}-233$ per year at $70 \%$ capacity factor. The U-233 produced supports 24,000 MWe of LWR capacity. System power levels are listed in Table 3. Note that $96^{\alpha}$ of the system's net electric production is by the fission reactors.

Results of our economic evaluation of this example fusion-fission system are given in Table 4. While our ability to estimate fusion breeder economics is primitive, economics is still an important aspect of our studies. Note that in this case the fusion breeder cost is quite high (4.4 B\$) but when divided by all the LWR': supported, the system capital cost is only $20 \%$ higher than the LWR's alone. The resulting system electricity cost is $43 \mathrm{mills} / \mathrm{kw}-\mathrm{hr}$ which is onl: $215 \%$ higher than if the LWR's were using U-Pu recycle and $U_{3} 0_{8}$ at $90 \$ / \mathrm{kg}$. We estimate that this fusion breeder is competitive with $U_{3} 0_{8}$ at about $180 \$ / \mathrm{kg}$.

The uncertainty in our estimate of filsion breeder economics is large but because it can support many fission reactors, the uncertainty in system electricity cost is much smaller. for example, a $100 \%$ increase in U-233 cost leads to only about a $20 \mathrm{~b}$ increase in electricity cost, while a $50 \%$ decrease in $U-233$ cost results in a $10 \%$ decrease in electricity cost. This insensitivity to uncertainties in fusion breeder economics has been referred to as its "robustness." 17 For more details on this example fusion-fission system, see Ref. 18. 
What type of blanket is best? While we at Livermore believe the fission-suppressed blanket is best, it is still an unanswered question. One of the goals of EPRI's assessment ${ }^{10}$ was to compare blanket types. System economics for a tandem mirror fussion breader with three blanket types vs net breeder power are compared in Fig. 4. The three blaniket types are thorium metal-fast fission (Th-FF), uranium carbide-fast fission (UC-Fr), and the Be fission-suppressed blanket designated here as Th-FS. The Th-FS olanket was found to have some economis advantage over the other two but this advantage is reduced as oreeder net electric power increases. On the other hand when other characteristics are compared, at 800 MWe, for example (Table 5), we see striking differences in LWR poker supported $(21,000$ down to 6000 MHe), fusion power (2400 down to $700 \mathrm{MW}$ ), and breeder capital cost (4.1 down to $2.7 \mathrm{BS}$ ). The highest values are with the fission-suppressed blanket, the lowest with the uranium fast fission blanket.

What type of fusion driver is best? This question was also addressed in the EPRI study. ${ }^{10}$ As a representative economic compurison, fiy. 5 shows that all three major fusion approaches could make economically competitive drivers.

Major conclusions and recommendations of the 1980 EPRI Feasibility Assessment of Fusion-Fission are listed below.

1. $U_{3} O_{8}$ resource limitations are only a question of time.

Fusion-fission could eiminate the shartfail.

2. Fusion breeders could provide a ceiling on $\mathrm{U}_{3} \mathrm{O}_{8}$ real cost escalation 
in the 100 to $400 \$ / \mathrm{kg}$ range.

3. Commercial introduction needed it the 2000-2020 time frame.

4. Has potential for near-term impact on utility decision making.

5. The three confinement approaches considered--tokamak, tandem mirror and laser ICF--resulted in similar economics.

6. Cost and performance differences were due more to blanket/fuel cyctc choices.

7. A tokamak commerciai demo could be operational by 2000 with the tandem mirror and ICF demos following 5 years apart.

8. Blanket development may be the pacing element.

9. Fusion-fission should be made a viable energy option for the time when U $\mathrm{O}_{8}$ shortfall is anticipated.

10. Increasing conceptual design activity is needed.

11. Increased attention should be devoted to fission-suppressed blanket ioncepts.

i2. In-depth development scenarios are needed.

The U.S. fusion-fission funding in 1981 is 2 i.0 $\mathrm{M \$}, 0.7$ from the Department of Energy (DOE), and 0.3 from the Electric Power Research Institute (EPRI). The DOE funding supports Livermore and four subcontractors (TRW, General Atomic (n., Westinghouse, and ORNL) work ing on the Tandem Mirror Hybrid (Breeder) project with major emphas is on development of fussion-suppressed blanket concepts. The EPR! funding supports Combustion Engineering $C_{0}$. on a project appraising past blanket designs. 
fus ion development. Fusion development in the U.S. is scheduled to: demonstrate physics feasibility in the 1980's with TF in and MFTF-8; demonstrate engineering feasibility in the $1990^{\prime}$ 's with the fusion engineering device, FFD; and have a demo electric power plant operational by 2000 . The objectives and timetable for the U.S. fusion program are called for in the Magnet ic Fusion Energy Act of 1980. The FED could be a test bed for fusion breeder blankets as well as fusion oriver technology. The demo could be a fusion breeder demo, assuming blanket and fuel cycles are developed.

vep loyment

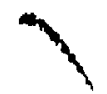

A major advantage we see of fusion-i ission is its ability to support a much faster and more timely growth in nuclear capacity than fission or fusion cauld alone. Conventianal fission (LWR, etc.) will run out of fuel. The fission breeder (LMFBR's) will be limited fir.t by the historical limitation on the intruduction of a new technology than by its doubling time when the pu stockpile is exhausted. Fusion electric deployment will also be limited by introduction constraints.

So even with the successful commercial introduction of fission breeders and fusion electric, an energy shortfall is very likely as oil, gas, and uranium resources are exhausted. The fusion breeder, by virtue of its high support ratio, could provide the stepping stone needed to bridge the energy gap (shortfall) while the fission breeder and/or fusion electric are being introduced. 
For example, consider the following U.S. scenario.

Nuclear generation goals

$250 \mathrm{GW}$ (electric) of LWR in 2000 (21\% of demand)

$1900 \mathrm{GW}$ (electric) nuc lear in 2060 (50N of demand)

Requires nuclear growth of $3.4 \% / y r$

\section{LWR assumptions}

$\mathrm{U}_{3} \mathrm{O}_{8}$ resource limit of 3 million tonnes

Utilities must see $30-y r \quad U_{3} O_{8}$ supply to comit to a new LWR

Plutonium is recovered and stockpiled for use in LMFBR's

\section{LMFBR assumptions}

First commerical plant in 2005, $8 \mathrm{GH}$ (electric) in 2020

$25 \% / y r$ growth after 2020 unt $i 120$ plant/yr limit is reached

$20 \mathrm{plant} / \mathrm{yr}$ until growth $=10 \% / \mathrm{yr}$

$10 \% / y r$ until plutonium stockpile consumed then limited to 18-yr

doubling time

\section{Fusion breeder assumptions}

First commercial plant in 2015

Initial introduction rate same as LMFBR

30 plants on line in 2037 (each 4000 MW-nuclear, $6200 \mathrm{~kg}$ fissile/yr)

The projected effect of 30 fusion breeders on U.S. nuclear capacity is substantial. As shown in Fig. 6, without these fusion breeders, LWR expansion would stop in 2020 and LMFBR construction is not sufficient to keep nu'lear's market share from dropping back to $\approx 20 \%$ in $\approx 2035$. By 2060 LMFBR construction has increased nuclear's market share to $\sim 37 \%$ but this is 
$\checkmark 500 \mathrm{GW}$ short of the $50 \%$ nuclear goal.

With the fusion breeder, LWR expansion could continue untıl LMFBR expansion couid catch up and continue to expand independent of its doubling time coristraints. For this example, 30 fusion breeders would allow nuclear to meet $60 \%$ of the demand in 2060, 1000 GW more than fission could alore. If fission breeders were not deployed, additional fusion breeders could be used to proside fuel for LWR's to meet the nuclear goal.

If fusion development is successful and deployment is like the LMFBR except 10 years later, but the fusion breeder option is not exercised, fusion + fission breeders could meet the long-term nuclear goal (after $~ 2055$ ). 3ut in the shorter term nuclear would miss its goal by a much wider margin. For this example, in 2040, ther'e is $~ 2700$ GWe less ruclear with fusion but without the fusion breeder.

While the deployment scenario just described is speculative, it is a goot example of the fusion breeder's potential deployment advantages.

In summary the fusion breeder:

1. Could have a significant role in nuciear power develo; ment and deployment, both fission and fusion, for it al lows fission to meet the demond with a variety of reactor types and is an earlier commercial 
mission for fusion.

2. Could be ready in time to help avert serious energy or enviromental problems in the 21 st century if fusion's development time table is met.

3. Is showing favarable economics, $<30 \%$ increase in energy costs, based on preliminary studies and is very robust. It would put a cap on $\mathrm{U}_{3} \mathrm{O}_{8}$ price.

4. Gives utilities the option of just buying fissile fuel, like they do now from enrichment plants.

5. Could have a very high benef it/cost ratic.

6. Is a near-term application; serious development should start now. 


\section{References}

1. D. H. Imhoff, et al., "A Oriven Thermonuclear Power Breeder, " CR-6, Cal ifornia Research arid Development Corporation (1954).

2. J. W. Weale, H. Goodfellow, M. H. Mcljaggart, and M. L. Mullender, J. Nucl. Energy A/B, 14, 91 (1961).

3. L. M. Lidsky, "Fission Fusion Symbios is: General Considerations and a Specific Examp?e," Proc. Br. Nucl. Energy Soc. Nucl. Fusion Reactor Conf. (Cu Iram Lab. 1969), pp. 41-53, CuTham Laboratory Report CLM-MFE 1969.

4. J. D. Lee, "Neutronics of Sul-Critical Fast Fission Blankets for D-T Fusion Reactors," Proc. 7th In tersociety Energy Conversion Engineering Conf., San Diego, CA, 1972, p. 1294, American Chemical Society (1972); see aisn UCRL-73952, Lawrence Livermore National Laboratory (1972).

5. 0. J. Bender, Ed., "Reference Jesign for the Standard Mirror Hybrid Reactor," UCRL-52478, GA-A14750́. a joint r'port by Lawrence Livermore Nationa 7 Laboratory and Ceneral Atomic Company (1978).

6. T. K. Fowler and B. G. Logan, "The Tandem Mirror Reactor, " Comments on Plasma Physics and Controlled Fusion Research, 2, 167 (i977).

7. J. D. Lee, "The Beryllium/Molten Salt Blanket," Lawrence Livermore National Laboratory Report UCRL-82663 (1979); also published in Proceedings of the 3rd US/USSR Symposium on Fusion-fission, Princeton, NJ T7979).

8. J. D. Lee and R. W. Moir, "Fission-Suppressed B!ankets for Fissile Fuel Breeding Fusion Reactors," Journal of Fusion Energy, 1, 3 (1981).

9. R. W. Moir, et al., "Tandem Mirror Hybrid Reactor Design Study Annual Report," Lawrence Livermore Nationa? Laboratory, Livermore, CA, UCRL-18808 (1980).

10. D. L. Chapin, Ed., "Prel iminary Feasibility Assessment of Fusion-Fission Hybrids, EPRI Project RP-1463, WFPS:TME-81-003 (1980).

11. 3. D. Lee, "Mirror Fusion-Fission Hybrids," Atomkernenergie/Kerntechnik (ATKE), 32 .

12. J. D. Lee, "Tandem Mirror Fusion-Fission Hybrid Studies," Lawrence Livermore National Laboratory, Livermore, CA, UCRL-84108, Rev. 1 (1980); a lso Atomkernenergie/Kerntechnik (ATKE), 36.

13. J. A. Maniscalco, et al., "Recent Progress in Fusion-Fission Hybrid Reactor Design Studies," Nuclear Technology/Fusion, 1, 4 (1981).

14. C. C. Baker, et al, "STARFIRE, A Commercial Tokamak Fusion Power Plant Study," ANL/PPP-80-1 (1980); also "An Overview in Inertial Conf inement 
Fusion," in Proc. 4th ANS Topical Meeting on the Technology of Controlled Nuclear Fusicin, King of Prussia, PA (Oct. 1980), p. 1074, CoNl 801011 .

15. G. A. Carlson, "The Design of Tandem Mirror Reactor's with Thermal Barriers," Proc. 4th ANS Topical Meeting on the Technology of Controiled Nuc lear Fusion, King of Prussia, PA (Oct. 1980), p. 815.

16. J. D. Lee, "Nuclear Design of the LLL-GA U USi Blanket," Proc. 3rd ANS Topical Meeting on Technology of Controlled Nuclear Fusion (May T979), p. 219, CONF780508.

17. D. J. Dreyfuss, B. H. Augenstein, W. F. Mooz, and P. A. Sher, "An Examination of Alternative Nuclear Breeding Methods, " Rand Report R-2267-DOE (1978).

18. J. D. Lee, et a1., "Parametric Systems Analys is for Tandem Mirror Hybrids," Proc. 4th ANS Topical Meeting on the Technology of Controlled Nuclear fusion, King of Prussia, PA (Oct. 1980), p. 1455, 
$-20-$ 


\section{TABLE 1}

\section{IDEAL BREEOING RATIO AND ENERGY RELEASE \\ WITH VARIOUS NEUTRON MULTIPLIERS}

\begin{tabular}{|c|c|c|c|}
\hline & BREEDING & & FISSILE AIOMS \\
\hline MULTIPLIERA & RATIOB & EAIERGY (MEV)B & PER MEVC \\
\hline U-238 & 4.2 & 190 & .017 \\
\hline TH232 & 2.4 & 50 & .028 \\
\hline $\mathrm{BE}$ & 2.7 & 22 & .077 \\
\hline $\mathrm{LI}$ & 1.8 & 16 & .050 \\
\hline $\mathrm{PB}$ & 1.7 & 19 & .037 \\
\hline
\end{tabular}

(A) PLUS FERTILE MATERIALS

(B) ATOMS OR ENERGY PER 14 SAEV DT FUSION NEUTRON

(C) (BREEDING RATIO - 1)/ENERGY 


\section{TABLE 2}

\section{PERFORMAMCE ESTIMATES FOR ENGINEERED BLANKETS}

\begin{tabular}{|c|c|c|c|}
\hline \multirow[b]{2}{*}{ BLANKET TYPE } & \multicolumn{2}{|c|}{ FAST FISSION } & \multirow{2}{*}{$\begin{array}{r}\text { FISSION } \\
\text { SUPPRESSED } \\
T H\end{array}$} \\
\hline & $U-238$ & TH & \\
\hline TRITIUM: BREEDING & 1.0 & 1.0 & 1.0 \\
\hline FISSILE BREEDING RATIO ${ }^{A}$ & 1.5 & 0.8 & 0.8 \\
\hline ENERGY i!ULT, $\langle M\rangle^{B}$ & 11 & 5 & 1.6 \\
\hline $\begin{array}{l}\text { FISETON POWER } \\
\text { DENSITY, PEAK }\left(W / \mathrm{CM}^{3}\right)\end{array}$ & 350 & 100 & 10 \\
\hline $\begin{array}{l}\text { FTSSSILE PRODUCTION } \\
\text { K.ATE }(\mathrm{KG} / \mathrm{Y})^{\mathrm{C}}\end{array}$ & 2700 & 2900 & 9600 \\
\hline $\begin{array}{l}\text { FISSLLN REACTOR POWER } \\
\text { SUPPORTED (MW) }\end{array}$ & 19,000 & 30.000 & 99.000 \\
\hline $\begin{array}{l}\text { NICLEAR SUPPORT } \\
\text { RATIOE }\end{array}$ & 5 & 9 & 25 \\
\hline
\end{tabular}
(A) NET ATOMS PER DT FUSION
(B) $M=$ ENERGY $/ 14$ MEV
(c) BREEDER POWER $=4000 \mathrm{MWN}_{\mathrm{N}}$
(D) LWR MAKEIP $142 \mathrm{KG}$ PU OR $97 \mathrm{KG} \mathrm{U-233} \mathrm{PER} \mathrm{GW-Y}$
(E) RATIO OF FISSION REACTOR POWER TO FUSION BREEDER POWER 


\section{TABLE 3}

\section{EXAMPLE FUSION-EISSION SYSTEM PQWER LEVELS}

\section{FUSION BREEDER}

\begin{tabular}{|c|c|}
\hline FUSION POWER & $2700 \mathrm{NW}$ \\
\hline NUCLEAR PONER LEVY! & $4000 \mathrm{MW}$ \\
\hline ELECTRIC POWER, GROSS & $2400 \mathrm{MHW}$ \\
\hline ELECTRIC POWER, NET & $1000 \mathrm{MW}$ \\
\hline $\begin{array}{c}\text { FISSILE (U-233) PROOUCTION. NET } \\
\text { (a 70\% CAPACITY FACTOR) }\end{array}$ & $6200 \mathrm{KG} / \mathrm{r}$ \\
\hline $\begin{array}{l}\text { ION REACTOR (LWR) POWER SUPPORTED } \\
\text { (ANNUAL U-233 MAKEUP }=255 \mathrm{KG} / G \mathrm{~W}_{E} \\
\text { a 70\% CAPACITY FACTOR) }\end{array}$ & $24.000 \mathrm{MW}_{E}$ \\
\hline
\end{tabular}

FISSION REACTOR (LWR) POWER SUPPORTED a $70 \%$ (APACITY FACTOR) 


\section{TABLE 4 \\ EXAMPLE FUSION-FISSION SYSTEM ECONOMICS (1980 S)}

TOTAL CAPITAL COST OF FUSION BREEDER

TOTAL CAPITAL COST OF LWRS

CAPITAL COST RATIO (LWRS + FB/LWRS)

SYSTEM ELECTRICITY COST

FISSILE MATERIAL (U-233) TRANSFER COST

EQUIVALENT $\mathrm{U}_{3} \mathrm{O}_{8}$ COST
$4.4 \mathrm{~B} \$$

870 \$/KWE

1.20

43 MILLS/KH-HR

$45 \$ 16$

$180 \$ / K G$

NOTE: CAPACITY FACTORS $=70 \%$, CAPITAL CHARGE $=15 \%$ PER YEAR 


\section{TABLE 5 \\ PARAMETERS FOR AN 800 MW NET BREEDER \\ WITH 3 BLANKET TYPES}

BLANKET TYPE

FUSION POWER, MW

CENTRAL CELL LENGTH, M

NET FISSILE PROOUCTION, KG/YR

LWR SUPPORT, GW(E)

TOTAL CAPITAL COST OF BREEDER, \$B

SYMBIOTTC SYSTEM COE, MILLS/KW-HR

TRANSFER COST OF FISSILE MATERIAL $\$ 1652.9$

EQUTV. COST OF U308 \$1KG
UC-FF

655

$980 \quad 2350$

22.5

34

81

$2120(P U) \quad 2600(U) \quad 5410(U)$

$6.0 \quad 10.0 \quad 21.1$

2.69

2.76

4.1

46.5

49.0

43.4

$87.5 \quad 51.0$

260

310

200 
FIG. 1. STARFIRE REFERENCE DESIGN

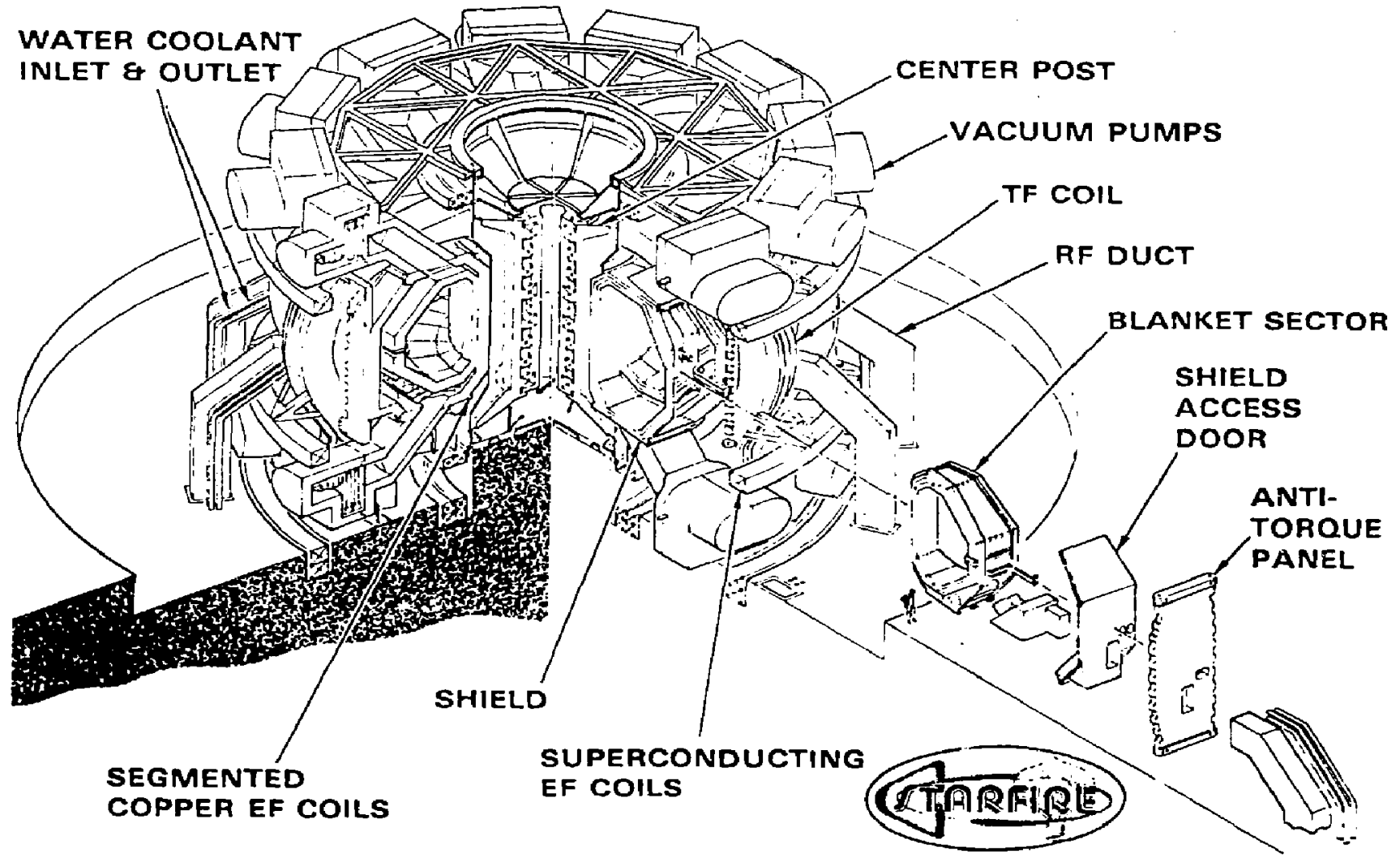




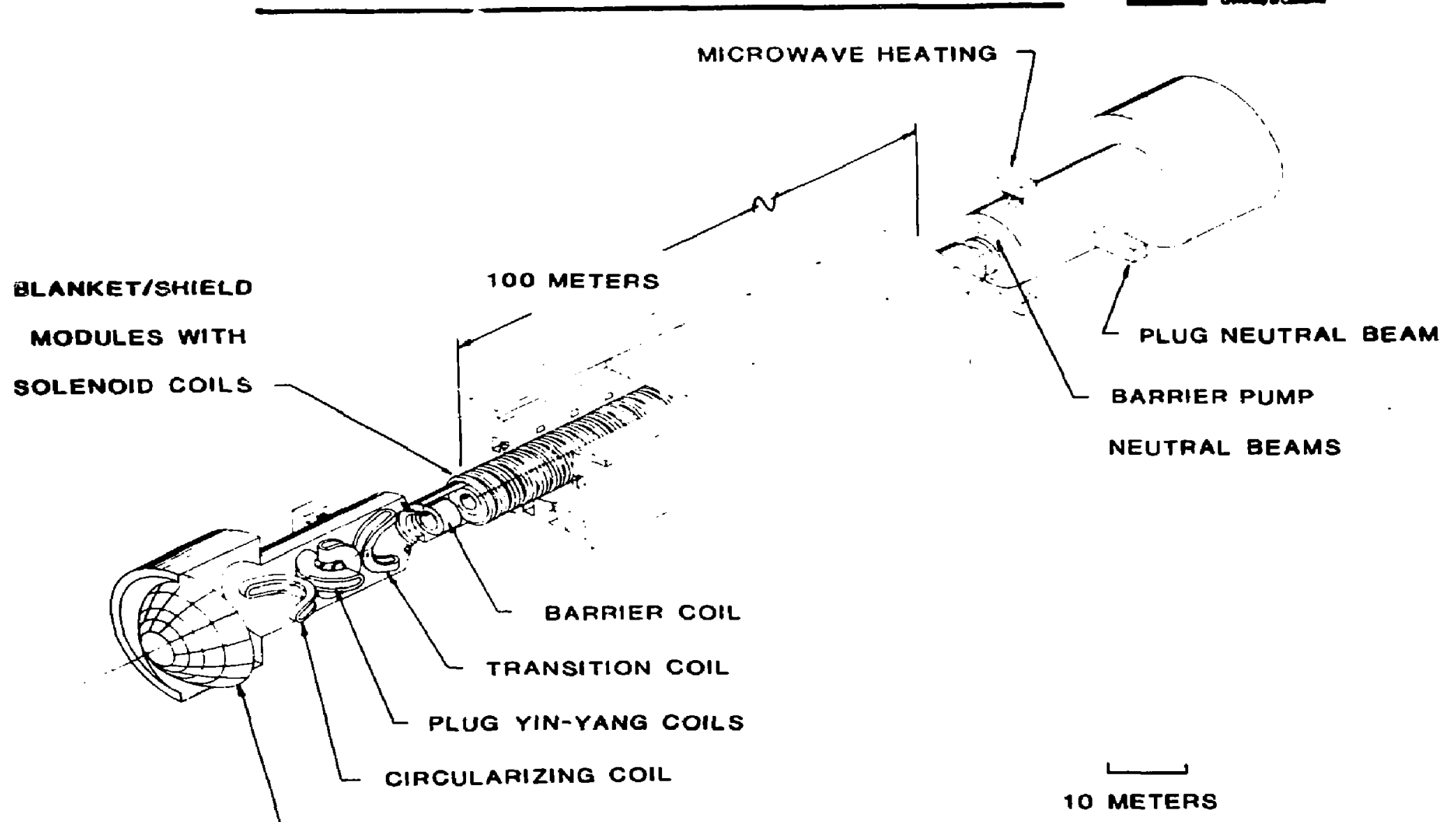


$+16.3$.

\section{The Blanket for the Tandem Mirror Consists of Cylindrical Modules}

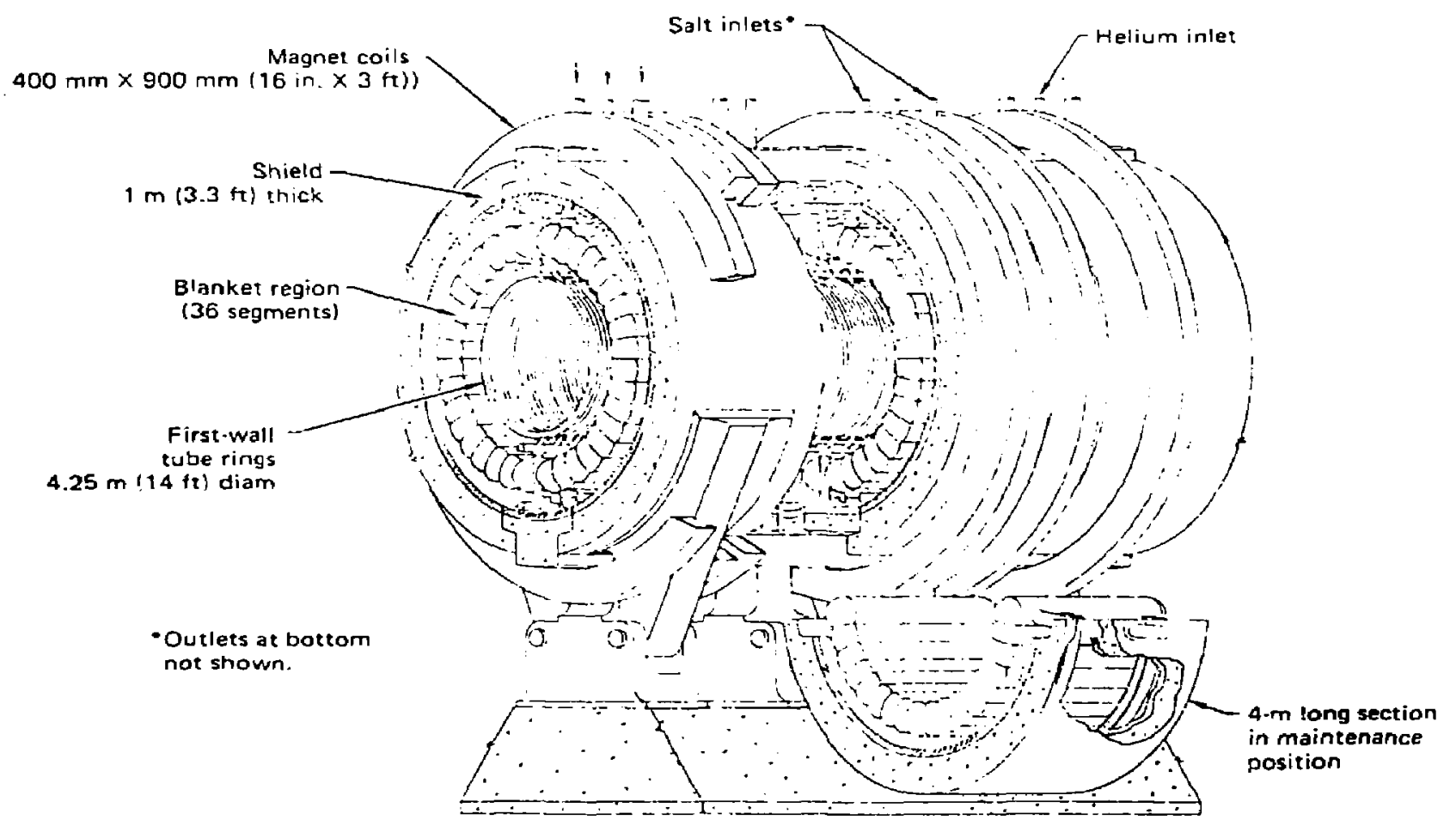


FIG, 4. SYSTEM POWER COST VS FUSION BREEDER NET POWER FOR 3 BLANKETS

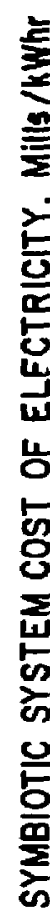

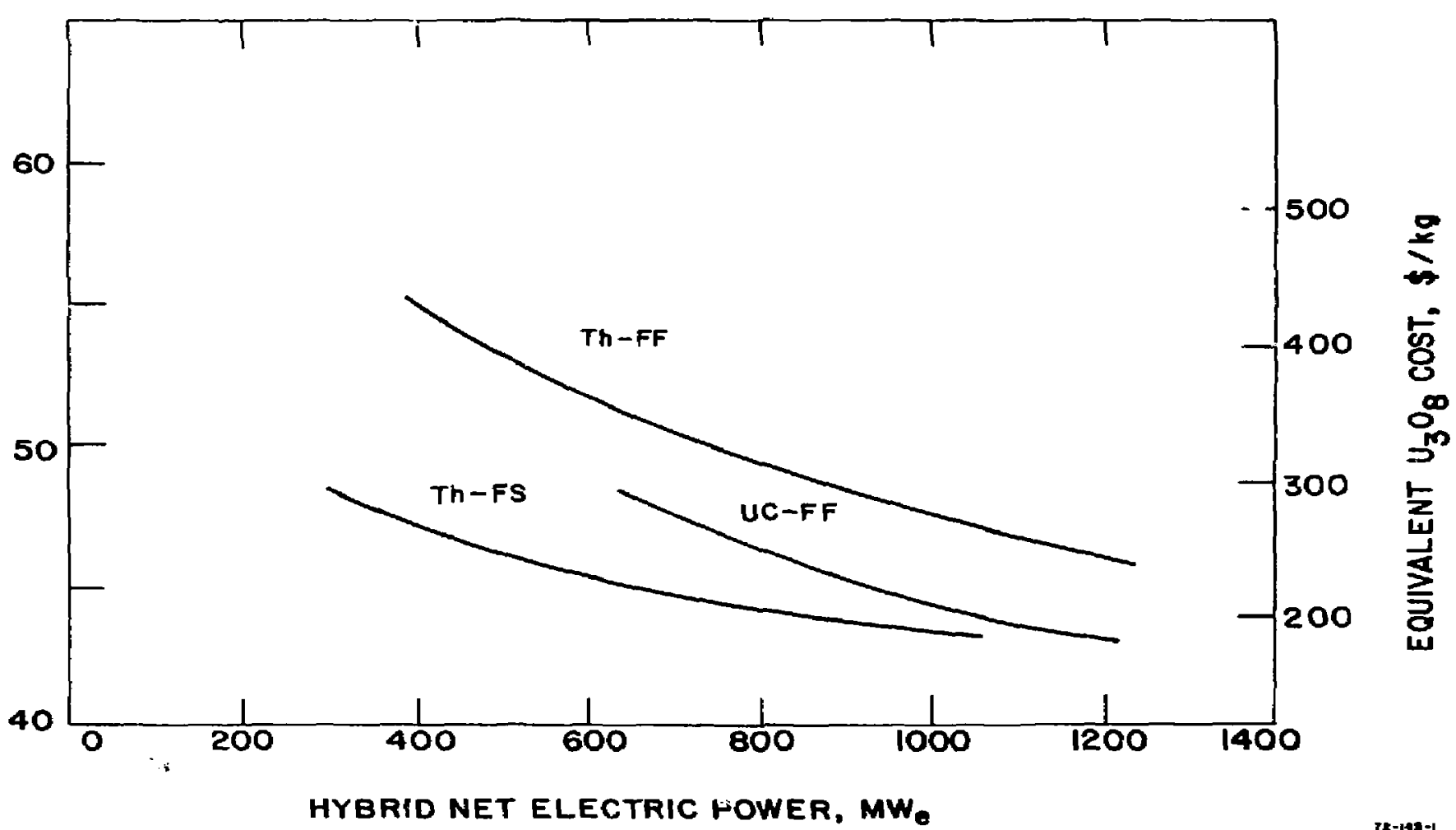


FIG, 5 ,

\section{Estimated Economics Vs Fusion Driver:}

(with thorium fission suppressed blanket)

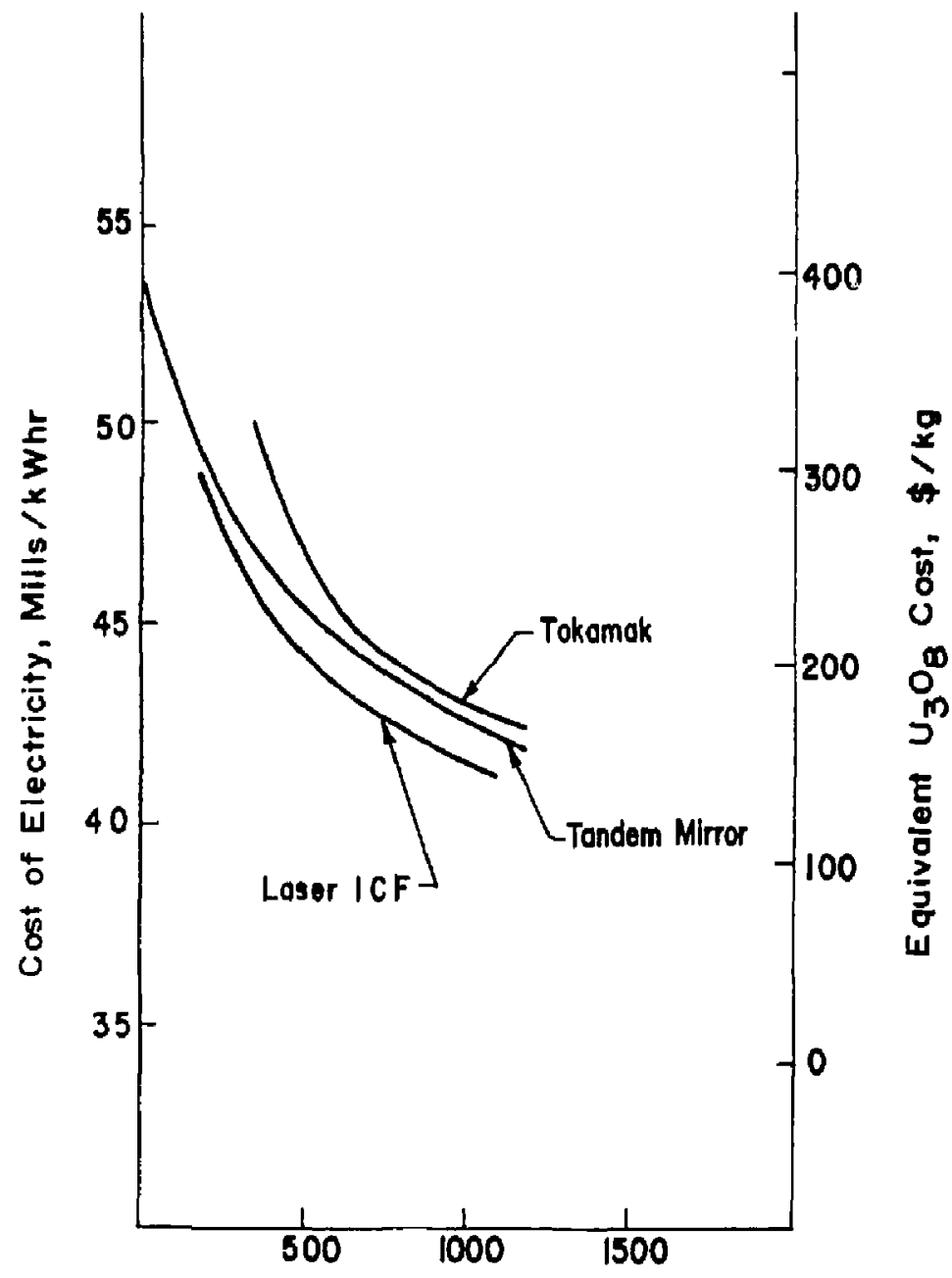

Fusion Broeder Nef Power, MW, 
FIG. 6

\section{U.S.NUCLEAR ELECTRICITY GENERATION PROJECTIONS}

-WITHOUT FUSION BREEDER $\left(3 \times 10^{6}\right.$ TONS $\left.\mathrm{U}_{3} \mathrm{O}_{8}\right)$

---WITH 30 FUSION BREEDER(HYBRIDS)DEPLOYED

\section{BETWEEN 2015 \& 2037}

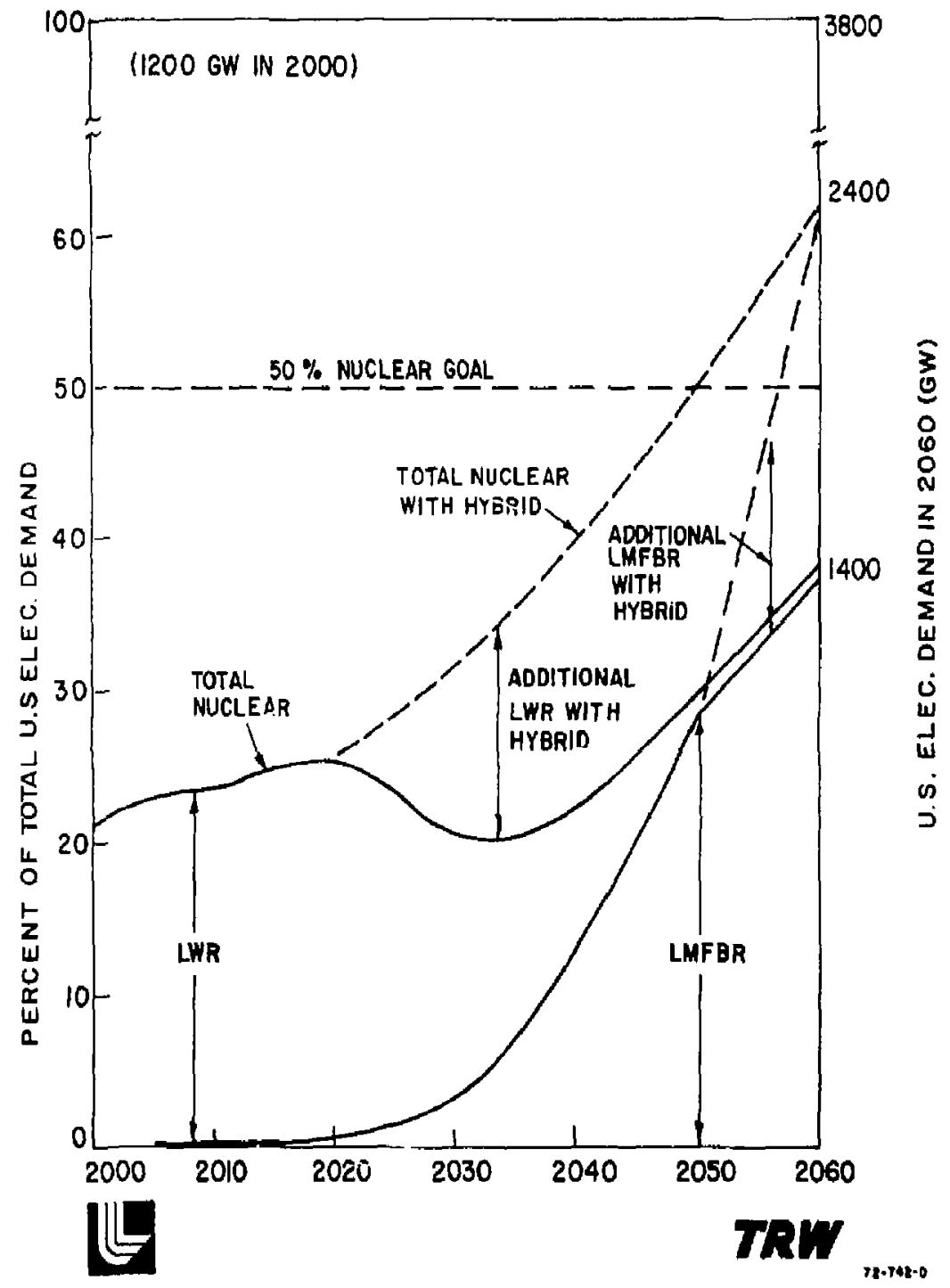

